Answer: Our objective is to characterize the effect of the grain structure on the eutectic percentage distribution with the measurements we perform, using a box size $0.5 \mathrm{~mm}$ along the solidification direction and $0.4 \mathrm{~mm}$ in width. The eutectic fraction measured at higher velocity in stage II is lower compared to the case at low velocity in stage I because the solidification proceeds by coarse columnar competitive growth at low velocity. Indeed, on the one hand, at low velocity, the competition with neighboring large dendrites with random orientation leads to the formation of quite large solute-enriched liquid pockets which are transformed into the eutectic phase at the end of solidification. On the other hand, in stage II, the microstructure at higher velocity, either columnar or equiaxed, is much finer due to the higher growth velocity, leading to a more uniform intergranular E\% distribution. This phenomenon was discussed in more details for other experiments in our previous study [Liu et al. Acta Materialia, 64 (2014) 253].

As our focus was on the pore formation for the present article, we did not develop the discussion on this important aspect. We now mention in the text that eutectic percentage in relation to the grain structure is characterized and briefly explain the difference observed between stages I and II. Moreover, we added a reference to previous work in the text. We thank the reviewer again for this comment. 


\title{
Effect of solidification conditions and surface pores on the microstructure and columnar-to-equiaxed transition in solidification under microgravity
}

\author{
Y. Z. Li ${ }^{(a)}$, N. Mangelinck-Noël ${ }^{(a), ~}{ }^{*}$, G. Zimmermann ${ }^{(b)}$, L. Sturz ${ }^{(b)}$, H. Nguyen-Thi ${ }^{(a)}$ \\ ${ }^{(a)}$ Aix-Marseille University, CNRS, IM2NP UMR 7334, 13397, Marseille, France \\ ${ }^{(b)}$ ACCESS e.V., Intzestraße 5, 52072 Aachen, Germany
}

\section{Abstract}

Microgravity solidification experiments were carried out in the Material Science Laboratory on board the International Space Station. The influence of grain refinement, rotating magnetic field (RMF) and surface pores on the microstructure and columnar-to-equiaxed transition (CET) were investigated in two selected Albased samples solidified under microgravity conditions. The increase of the furnace pulling velocity leads to a finer dendrite structure, a smaller eutectic percentage and a more uniform eutectic distribution in the interdendritic regions. On the one hand, grain refinement ensures the occurrence of $\mathrm{CET}$, which is progressive in the studied experiment because of the high temperature gradient. On the other hand, in the nonrefined alloy a RMF applied during solidification fails to trigger the CET, because the forced liquid flow is too weak compared to the solidification front velocity to transport fragments from the mushy zone above the solidification front. The presence of the pores at the sample surface leads to a peculiarity in the eutectic percentage and weakens the decrease of the dendrite arm spacing for both samples. These effects are ascribed to a forced extra liquid flow into the mushy zone due to the pore that 
promotes the growth of the dendrites along the liquid flow direction, resulting in elongated grains and postponing the CET in the refined alloy.

Keywords: Aluminum alloys; Solidification; Microgravity; Crystal structure; Columnar-to-Equiaxed Transition; Pore

\section{Introduction}

Morphological development during solidification remains of tremendous interest for both academic research and industrial applications, due to the tight relationship between the microstructures and the final properties [1]. Indeed, growth in a high temperature gradient may result in elongated columnar structures, whereas a more uniform temperature favors isotropic equiaxed grains. Accordingly, a change from columnar to equiaxed grain structure is often observed during industrial processes such as ingot casting or welding by a simultaneous decrease of the temperature gradient and an increase of the growth velocity. CET is an important morphological transition in metallic alloys, which is mainly controlled by the liquid undercooling ahead of the dendritic front [2]. CET occurs when the number of equiaxed grains and the volume they occupy become sufficient to block the columnar front [3-5].

Equiaxed grains have two main origins: purposely added nucleating particles and dendrite fragmentation. Industrially, the main approach to favor the equiaxed microstructure is to add grain refiners, which act as preferential sites for nucleation with a low nucleation undercooling [6, 7]. For non-refined alloys, the most potent mechanism for the origin of the equiaxed grains ahead of the columnar front is the dendrite fragmentation $[8,9]$, which is believed to be at the origin of the central equiaxed core region in casting processes. Fragmentation occurs when dendrite 
branches are detached from the main primary trunks, as well as from the secondary or higher order arms. Fragmentation is favoured by the dendrite coarsening process but also by the initiation of local remelting due to the pile-up of solute within the partially solid-liquid sample region (mushy zone) $[10,11]$. The additional effect of gravity force (buoyancy force or natural convection) [12] or the impact of thermoelectro-magnetic force [13] cannot be excluded in fragmentation phenomena. If these fragments are transported ahead of the columnar front by buoyancy forces or convection and if they can continue to grow, an equiaxed grains microstructure is formed that can stop the advancing columnar front. The competition of equiaxed grains with the advancing solidification front is a complex topic, which involves mechanical blocking as well as thermal and solutal interaction. J.D. Hunt proposed a geometrical criterion to explain this transition in terms of mechanical blocking [3], but it is now recognized that the dominant mechanism for the CET is the solutal blocking , due to solute rejection from growing equiaxed and columnar dendrites [5].

CET as well as the final microstructure features are strongly affected by gravity induced phenomena namely, sedimentation effect and coupling between flow and the solid-liquid interface. On Earth (1g), the melt flow plays a critical role in mass and heat transfer, and consequently affects the final microstructure, as well as the CET and the eutectic formation [14-17]. Microgravity experimentation is a perfect tool to deepen the study of CET, as it provides unique benchmark data by suppressing most of the gravity-driven phenomena during solidification, such as natural convection, as well as sedimentation or buoyancy. In microgravity environment, we can expect to achieve nearly diffusive conditions for transport [18-20]. Nevertheless, even in gravity-free conditions, fluid flow, generated by the sample shrinkage induced by the difference of solid and liquid densities, still exists [21, 22]. Another 
cause of fluid flow in gravity-free conditions is Marangoni convection [23, 24], due to the presence of free interfaces like liquid-gas surfaces. This contribution to convection is often negligible in directional solidification for which the only gas-liquid surface is at the top of the sample.

Porosities are considered as serious and common defects formed during solidification [25], which result in a significant degradation of the mechanical properties and act as the origin of crack initiation because of stress concentration [26-28]. Up to now, the formation of porosity has been considered by numerous investigations, but, as a matter of fact, mostly focusing solely on the pore formation mechanism [29-35]. It is generally accepted that the residual gases, which are mainly hydrogen, dissolve and accumulate at the solidification front, since gas solubility is often much less in the solid than in the liquid. As a result, bubbles readily nucleate to form porosities, not only at the crystal or dendrite interface, but also on the sample surface $[31,32,36]$. Also reactions between the melt and the crucible walls at elevated temperatures may play a role.

Except their impact on crack initiation, the porosities also affect the solidified microstructure by triggering the deformation of the dendritic network $[37,38]$ and creating Marangoni liquid flow around the pore region during the solidification [3942]. Indeed, it has been reported that the mushy alloy could deform under external loads [43-45]. The deformation mechanism changes with the increase of the solid fraction [43]. The spongy deformation of the mushy zone during the solidification is also reported by Lesoult et al., together with the effect on segregation [46]. Additionally, primary crystal deformation and flow of solute-enriched liquid towards the shear deformation plane have also been observed $[47,48]$. Therefore, combined with the Marangoni effect, the liquid flow triggered by porosity formation should also 
be considered for the microstructure transformation. However, these porosity impacts on the microstructure features and CET have rarely been mentioned in experimental or numerical investigations before, to the best of our knowledge.

Our investigations are conducted by means of directional solidification in microgravity conditions. The quantitative analyses of the eutectic fraction and the dendritic structure, as well as the CET are provided and correlated with the solidification parameters. In addition, the influence of a pore at the surface of a sample on the microstructure formation has been analyzed in detail.

\section{Experimental}

\subsection{Experiments}

The Material Science Laboratory (MSL) was made available by the European Space Agency (ESA) on board the International Space Station (ISS), providing a platform for microgravity solidification investigations. In the framework of the CETSOL (Columnar to Equiaxed Transition in SOLidification processes) ESA MAP (Microgravity Applications Promotion programme) project [49-51], thirteen microgravity experiments have been conducted in two batches named Batch 1 and Batch 2a. The six samples in Batch 1 were carried out using the Low Gradient Furnace (LGF), which have presented and discussed in detail in a previous study [19]. The samples in Batch 2a, which are the objects in this paper, were carried out using the Solidification and Quenching Furnace (SQF), which is also a directional solidification furnace but allows higher temperature gradient and cooling rate compared to the LGF.

The full SQF and the sample cartridge assembly (SCA) are schematized in Fig.1. It consists of a hot and a cold zone separated by a so-called adiabatic zone. The cold 
zone is realized by a Liquid Metal Ring (LMR) to achieve a high temperature gradient (up to $8 \mathrm{~K} / \mathrm{mm}$ in this SCA) and to allow for quenching. The hot zone is equipped with four heaters $\mathrm{H} 1-\mathrm{H} 4$, which can be adjusted independently to achieve the required temperature gradient along the sample axis. Solidification of the alloy is performed by the controlled displacement of the SQF along the fixed SCA at a chosen velocity, which can be varied during the experiment. The metallic alloy sample (8 $\mathrm{mm}$ in diameter and $245 \mathrm{~mm}$ in length) is mounted inside a protective $\mathrm{Al}_{2} \mathrm{O}_{3}$ tube crucible together with Shapal plugs at both bottom and top ends. Twelve $\mathrm{N}$-type (Nicrosil-Nisil) thermocouples (TC1-TC12), spaced by $20 \mathrm{~mm}$, are located in four machined external axial grooves at the outer surface of the crucible to measure the temperature profile (purple dots in Fig.1).

In the present work, a comparative study of two samples, labelled B2F1 and B2F2, from Batch $2 \mathrm{a}$ is conducted. The solidification conditions of the two selected experiments are the same in terms of temperature gradient and furnace pulling velocity profiles to allow direct comparison (see Table 1). The two major differences between the two samples are: (I) B2F1 is a grain refined alloy sample $(\mathrm{Al}-7 \mathrm{wt} \% \mathrm{Si}+$ 0.5 wt\% of master alloy AlTi5B) whereas B2F2 is a non-refined Al - 7 wt.\% Si alloy and (ii) a rotating magnetic field (RMF) is applied during the second stage of the experiment B2F2 to analyze the impact of moderate forced fluid flow on CET in $\mu \mathrm{g}$ environment. The Al - 7 wt.\% Si alloys were provided by Hydro Aluminum Rolled Products $\mathrm{GmbH}, 0.5 \mathrm{wt} \%$ of master alloy AITi5B was added to the sample for refinement. The rotating magnetic field (RMF) applied during stage II for B2F2 has a frequency $f=57 \mathrm{~Hz}$ and a magnetic field strength of $B=0.5 \mathrm{mT}$. 
Table 1: Control parameters for the two selected samples solidified under microgravity: $v_{n}$ is the furnace pulling velocity and $z_{n}$ the furnace movement with $v_{n}$ in phase $n$. Sample with notation grain refiner contains $0.5 \mathrm{wt} \%$ of master alloy AITi5B for grain refinement.

\begin{tabular}{|c|c|c|c|c|c|c|c|c|c|}
\hline \multirow{2}{*}{ Sample } & \multirow{2}{*}{ Alloy } & \multirow{2}{*}{$\begin{array}{c}\text { Initial G, } \\
\mathrm{K} / \mathrm{mm}\end{array}$} & \multicolumn{2}{|c|}{ Stage I } & \multicolumn{4}{|c|}{ Stage II } & \multirow[t]{2}{*}{ Stage III } \\
\hline & & & $\begin{array}{c}\mathrm{v}_{1} \\
\mathrm{~mm} / \mathrm{s}\end{array}$ & $\begin{array}{l}\mathrm{z}_{1} \\
\mathrm{~mm}\end{array}$ & $\begin{array}{c}\mathrm{v}_{2} \\
\mathrm{~mm} / \mathrm{s}\end{array}$ & $\begin{array}{l}\mathrm{z}_{2} \\
\mathrm{~mm}\end{array}$ & $\begin{array}{l}\mathrm{R} \\
\mathrm{K} / \mathrm{s}\end{array}$ & RMF & \\
\hline $\mathrm{B} 2 \mathrm{~F} 1$ & $\begin{array}{c}\text { Al }-7 w t \% S i+\text { grain } \\
\text { refiner }\end{array}$ & 4 & 0.02 & 20 & 0.2 & 50 & 0.133 & No & Quenching \\
\hline B2F2 & $\mathrm{Al}-7 \mathrm{wt} \% \mathrm{Si}$ & 4 & 0.02 & 20 & 0.2 & 50 & 0.133 & Yes & Quenching \\
\hline
\end{tabular}

The solidification profile consists of three successive stages:

- Stage I: The initial applied temperature gradient $(\mathrm{G})$ is $4 \mathrm{~K} / \mathrm{mm}$. Solidification is initiated by the furnace motion for $20 \mathrm{~mm}$ at a low pulling rate $(0.02 \mathrm{~mm} / \mathrm{s})$ in order to form a columnar microstructure in stationary conditions.

- Stage II: The second stage is triggered by a sudden pulling rate jump from 0.02 $\mathrm{mm} / \mathrm{s}$ to $0.2 \mathrm{~mm} / \mathrm{s}$. This new pulling rate is applied for a movement of $50 \mathrm{~mm}$ together with a cooling down of the hot zone with $0.133 \mathrm{~K} / \mathrm{s}$. The simultaneous increase of the growth velocity and decrease of the temperature gradient are expected to induce the CET. Additionally for B2F2, a rotating magnetic field (RMF) with frequency $f=57 \mathrm{~Hz}$ and magnetic field strength of $B=0.5 \mathrm{mT}$ was applied to induce a moderate forced melt flow in the sample.

- Stage III: The quenching of the sample induced by a fast furnace pulling is applied to complete the solidification. During this final quenching stage, the temperature gradient and cooling rates are no longer controlled, but the temperature profile is still recorded. 


\subsection{Microstructure characterization}

The characterization methods in the present study are similar with our previous study [19]. For metallographic analysis, the solidified samples are cut into parts of $30 \mathrm{~mm}$ in lengths. The sketches of the cutting positions of the two samples are shown in Fig. 2 together with images of the processed samples. Then, longitudinal sections cut close to the centerline are mechanically polished with diamond suspension to reveal the dendritic structures by optical microscopy (OM).

First, the optical microscopy images of longitudinal sections L2 and L3 for B2F1 and sections L1 and L2 for B2F2 are segmented into binary images using a threshold to separate the two phases: the dendrite phase appears in white, while the eutectic is black. Based on those binary images, the eutectic percentage (E\%) maps and the profiles of $\mathrm{E} \%$ along the solidification direction, i.e. along the main cylindrical sample axis are determined using a box-averaging method, as well as dendrite arm spacing (DAS) using the linear-intercept method [19]. The box size for E\% maps is $0.5 \mathrm{~mm}$ in length, in the direction of the sample central line axis, and $0.4 \mathrm{~mm}$ in width. The box size for both E\% and DAS profiles is $0.5 \mathrm{~mm}$ in length and equal to the sample diameter in width. For one data point of DAS, 1000 lines are generated in random orientation in each box for accurate results. It is worth mentioning here that the DAS measured with this method is not equal to the primary or secondary dendrite arm spacing but a measurement of the average characteristic scale of the dendritic network $[19,52]$.

In a second phase of analysis, Electron backscattered diffraction (EBSD) of sections L2 and L3 for B2F1 was performed to analyze the grain structure more accurately. The EBSD measurement was carried out only for B2F1 sample, because it appears 
clearly that there is no CET during B2F2 experiment. The EBSD measurement was performed for the entire longitudinal sections with a scanning step of $8 \mu \mathrm{m}$. Based on EBSD data, the grain contours were reconstructed by separating neighboring grains with their misorientation being larger than $5^{\circ}$. The grain equivalent diameter (ED, defined as the diameter of a circle of equivalent grain area) and elongation factor (EF, defined as the ratio of the length of the major axis to the minor axis of a grain), are calculated from the EBSD measurements. The grains cut by the section boundaries were excluded in the calculation.

\section{Results}

\subsection{Analysis of the processing parameters}

The recorded cooling curves for both $\mathrm{B} 2 \mathrm{~F} 1$ and $\mathrm{B} 2 \mathrm{~F} 2$ are shown in Fig.3a and b, with identification of the three stages delimited by the starting time points of the furnace movement of every stage. From Fig.3a and b, it can be seen that the thermal histories recorded are very similar for $\mathrm{B} 2 \mathrm{~F} 1$ and $\mathrm{B} 2 \mathrm{~F} 2$, indicating that the addition of grain refiner (GR) and the application of RMF in stage II have negligible influence on the recorded temperatures and thus on the heat flow for the present experiments. The negligible impact of GR on thermal distribution in the sample is expected, due to the very small amount of GR. On the contrary, the absence of RMF effect is more surprising, taken into account that a liquid flow is likely driven by the RMF [53]. This issue is discussed later in the paper.

To evaluate the relationship between the microstructure and the actual thermal conditions, the temperature gradient $G$ (Fig.3c) and the velocity of the liquidus isotherm $v$ (Fig.3d) are calculated based on the temperature profiles of the thermocouples. The procedure to produce these data is similar to the method 
described by Ch-A. Gandin [54] and in our previous work [19]. The temperature gradient ahead of the liquidus isotherm is calculated at the time when the liquidus isotherm ( $T_{L}=891 \mathrm{~K}$ for $\left.\mathrm{Al}-7 \mathrm{wt} . \%\right)$ reaches a thermocouple. Moreover, by following the liquidus isotherm position in time, the velocity of the liquidus isotherm can be deduced. Using linear interpolation, the average temperature gradient and velocity of the liquidus isotherm are calculated every $10 \mathrm{~mm}$. Additionally, the average values of the calculated temperature gradient and velocity of the liquidus isotherm for each stage, as well as the corresponding standard deviation are shown in Table 2.

Table 2: The calculated average temperature gradient $G$ and the corresponding standard deviation $\sigma_{<G>}$, the calculated average velocity $v$ at the liquidus isotherm and the corresponding standard deviation $\sigma_{<V>}$, the averaged eutectic percentage (E\%) and dendrite arm spacing (DAS).

\begin{tabular}{cccccccc}
\hline Sample & Stage & $\langle\mathrm{G}>, \mathrm{K} / \mathrm{mm}$ & $\sigma_{<\mathrm{G}>}, \mathrm{K} / \mathrm{mm}$ & $<\mathrm{V}>, \mathrm{mm} / \mathrm{s}$ & $\sigma_{<\mathrm{V}>}, \mathrm{mm} / \mathrm{s}$ & $\mathrm{E}, \%$ & $\mathrm{DAS}, \mu \mathrm{m}$ \\
\hline \multirow{2}{*}{$\mathrm{B} 2 \mathrm{~F} 1$} & $\mathrm{I}$ & 4.4 & 0.1 & 0.02 & 0.003 & 57.5 & 55 \\
& $\mathrm{II}$ & 4.8 & 0.3 & 0.11 & 0.043 & 46.2 & 33 \\
& $\mathrm{I}$ & 4.5 & 0.1 & 0.02 & 0.003 & 55.2 & 57 \\
B2F2 & $\mathrm{I}$ & 4.8 & 0.3 & 0.11 & 0.047 & 47.6 & 35 \\
\hline
\end{tabular}

The curves in Fig. $3 \mathrm{c}$ and $d$ show that the processing conditions of the two samples are very similar during the whole experiment and confirm the negligible influence of the GR and RMF on the thermal growth conditions during the solidification process. For the stage I, only one value can be obtained from the TCs for the temperature gradient $(\mathrm{G}=4.4 \mathrm{~K} / \mathrm{mm}$ for $\mathrm{B} 2 \mathrm{~F} 1$ and $\mathrm{G}=4.5 \mathrm{~K} / \mathrm{mm}$ for $\mathrm{B} 2 \mathrm{~F} 2)$ and the isotherm velocity $(0.02 \mathrm{~mm} / \mathrm{s}$ for both samples). These values correspond to the applied 
nominal values. After the application of new solidification conditions (during stage II), the temperature gradient increases up to $G=5.2 \mathrm{~K} / \mathrm{mm}$ for B2F1 (resp. $G=5.1$ $\mathrm{K} / \mathrm{mm}$ for B2F2), while the growth velocity increases to a maximum value of $\mathrm{v}=0.14$ $\mathrm{mm} / \mathrm{s}$ for B2F1 (resp. $\mathrm{v}=0.15 \mathrm{~mm} / \mathrm{s}$ for B2F2). The discrepancy between those values and the applied nominal ones might be attributed to a change of the solidliquid interface position relatively to the LMR (Fig.1) when increasing the furnace pulling rate. Finally, the quenching of the sample induces a sharp increase of both the growth velocity and the temperature gradient.

Additionally, the average values of $G$ and $v$ during stage I and stage II are given in Table 2 together with the corresponding standard deviations. As shown in Table 2, the mean values of the calculated $G$ and $v$ are about $4.4 / 4.5 \mathrm{~K} / \mathrm{mm}$ and $0.02 \mathrm{~mm} / \mathrm{s}$ in stage I, and then increase to about $4.8 \mathrm{~K} / \mathrm{mm}$ and $0.11 \mathrm{~mm} / \mathrm{s}$ in stage II for both samples. The length of the mushy zone $\left(L_{M z}\right)$ during the solidification process, defined as the distance between the liquidus and eutectic isotherms was also calculated. The average values of the $\mathrm{L}_{\mathrm{MZ}}$, for both $\mathrm{B} 2 \mathrm{~F} 1$ and $\mathrm{B} 2 \mathrm{~F} 2$ samples, are estimated at about $9.5 \mathrm{~mm}$ and $8.0 \mathrm{~mm}$ in stage I and II, respectively.

\subsection{Analysis of the microstructure}

Microstructures in longitudinal sections are shown in Fig.4 (a1 and b1). The bottom position in both figures corresponds to the start of the solidification process. The blank region between stage I and stage II is due to the material loss during the sample cut and the transverse section preparation. The furnace pulling velocities corresponding to the different solidification stages are marked out at the left side, based on the transition positions between successive stages determined in Fig.3c 
and $\mathrm{d}$. The eutectic percentage (E\%) distribution maps of the same regions are also shown in Fig.4 (a2 and b2).

In stage I of both samples, a columnar structure is obtained growing from the initial partially melted mushy region. From stage I to stage II, the microstructure significantly changes for $\mathrm{B} 2 \mathrm{~F} 1$ and $\mathrm{B} 2 \mathrm{~F} 2$. In $\mathrm{B} 2 \mathrm{~F} 1$, large columnar dendrites are observed in stage I, whereas equiaxed grains and much finer dendrite grains are obtained in stage II. The starting position of the equiaxed grains microstructure is about $134 \mathrm{~mm}$, as shown by the red dash line in Fig.4a1. For B2F2, the dendrite structure remains columnar in both stages I and II, but with a transition from a coarse to a finer dendrite microstructure. Nevertheless, surface pores are visible around 147 $\mathrm{mm}$ in stage II in both samples, which can also be seen from the images of the two samples as shown in Fig.2.

The eutectic is formed due to the solute rejection and accumulation in the interdendritic regions. For both samples, some quite large eutectic regions due to competition between randomly oriented columnar grains, up to $3 \mathrm{~mm}$ in length, are found in stage I and as a consequence, inhomogeneous distribution of the eutectic percentage is observed. At the transition from stage I to stage II, a similar change is found for both experiments. First, the size of the eutectic zones significantly decreases just after the pulling rate jump and the eutectic distribution is much more uniform, with a lower average eutectic percentage. This is a consequence of the finer dendritic microstructure during the stage II and has been discussed in more details in our previous work [19].

To better understand the evolution of the microstructure during the solidification, the analysis of the average eutectic percentage (E\%) and dendrite arm spacing (DAS) along the sample axis has been done for both samples. In this calculation, the 
regions affected by the surface pores are excluded in a first step. The averaged longitudinal profiles of the E\% and DAS along the solidification direction are shown in

Fig.5. Furthermore, the corresponding stage-averaged E\% and DAS in each stage are also gathered in Table 2. As shown in the profiles in Fig.5, both the E\% and DAS continuously decrease from stage I to stage II in both B2F1 and B2F2 as well as in average according to the increase of the liquidus isotherm $v$ (Table 2). The differences of the average $\mathrm{E} \%$ and DAS values between $\mathrm{B} 2 \mathrm{~F} 1$ and $\mathrm{B} 2 \mathrm{~F} 2$ are minor in both stages I and II.

\subsection{Analysis of the columnar to equiaxed transition (CET)}

Considering the grain structure observed by OM, sample B2F1 presents a CET from stage I to stage II. The CET is progressive and not sharp and its limits are defined according to previous work [19]. The highest position of the columnar grains issued from the initial dendrites zone defines the CET inception [55], and is noted CET $\min$ in Fig.4a1 (about $134 \mathrm{~mm}$ for B2F1). The uncertainty on this position is due to the cut of a transverse section between sections L2 and L3. As concerns B2F2, no CET is observed along the entire sample.

In our previous work [19], it has been shown that $C E T_{\min }$ is not sufficient to define CET, especially when very elongated equiaxed grains are observed above this position. A second limit for complete CET, CET max, is defined using grain morphological characterisation. Indeed, according to Hunt and Biscuola $[3,56]$, the complete transition from columnar to equiaxed grain growth can be characterized by the change of grain size and morphology. A critical value of the elongation factor (EF) of the grains was deduced from the mechanical-blocking fraction of the equiaxed grains to quantitatively define the CET. Grains are considered to be fully 
equiaxed when the EF value is below 2 and this gives the criterion to determine $\mathrm{CET}_{\max }$ position here. The grain structure is quantitatively analyzed using EBSD measurement data of sections L2 and L3. The constructed grain contour maps are displayed in Fig.6a. Fig.6b shows the average equivalent diameter (ED) and elongation factor (EF) along longitudinal sections. Each data point is obtained by the average value of 15 grains sharing closest gravity centre position. The average position of these grains is taken as the representative position of the corresponding average ED and EF.

The results show that, both the ED and the EF of B2F1 sharply decrease from stage I to stage II. When excluding (not shown here) the region around the surface pore position (147 mm), the ED of all the grains and the EF of most of the grains remain at a low value after the transition from stage I to stage II. The EF mainly stays close but slightly above 2 after $\mathrm{CET}_{\min }$ up to $156 \mathrm{~mm}$, which is close to the transition

position from stage II to stage III. Based on the characterization of the ED and the criterion on the EF, the grain structure after $\mathrm{CET}_{\min }$ is equiaxed but elongated between $134 \mathrm{~mm}$ and $156 \mathrm{~mm}$, and is fully equiaxed after $156 \mathrm{~mm}$, which is the transition position from stage II to stage III, referred to as $\mathrm{CET}_{\max }$, as shown in Fig.6b. Such a region with elongated equiaxed grains defines a progressive CET in B2F1 $[19,57]$

\subsection{Analysis of the microstructure and CET at the level of surface pores}

It can be seen from Fig.5, that irregular E\% is clearly detected at the position around $147 \mathrm{~mm}$ in stage II for both B2F1 and B2F2, which is exactly the location of the surface pores as shown in Fig.4 (a1 and b1). Concerning the DAS profiles, a moderate slow-down of the DAS decrease is observed at the same position. In order 
to focus on the effect of the pore, the microstructure and the longitudinal profiles of the E\% and DAS around this position are compared in Fig.7.

It can be seen in Fig.7 ( $\mathrm{a}$ and $\mathrm{b}$ ) that the lengths of the pore regions, about $6 \mathrm{~mm}$ for $\mathrm{B} 2 \mathrm{~F} 1$ and $10 \mathrm{~mm}$ for $\mathrm{B} 2 \mathrm{~F} 2$, are comparable to the sample diameter and to the length of the mushy zone calculated in section 3.1. Additionally, no obvious distortions of the primary dendrites are observed around the pore region for both samples.

It can be seen in Fig.7c that the value of the $E \%$ is stable in the region far below the pore for B2F1 (below $z=143 \mathrm{~mm}$ ). Then, it starts to decrease at about $1 \mathrm{~mm}$ below the pore start position. The E\% stabilizes again until it starts to increase below the pore end, up to about $1 \mathrm{~mm}$ behind the pore end. After that, the E\% returns to a constant value. The variation of the E\% for B2F2 is significantly different from B2F1. The E\% firstly decreases with a low slope in the region far from the pore and then starts to decrease with a higher slope at a position close to the start of the pore. When the pore is about to end, the E\% increases until the end of the pore and then starts again to decrease, extending to the region far from the pore.

The variation of the DAS shows a continuously decreasing trend but with different decrease slopes around the surface pore region for both $\mathrm{B} 2 \mathrm{~F} 1$ and $\mathrm{B} 2 \mathrm{~F} 2$. The decrease slope of DAS around the pore region is slightly lower than in the region far from the pore, both before or after the pore region. Especially, the DAS value is almost stable around the pore region for B2F1.

Furthermore, on top of the effect on E\% and DAS profiles around the pores, an irregular increase of EF is observed for B2F1 at this position (Fig.6b). This indicates that the presence of the pore enhances the elongated growth of the grains in this region, indicated by the red circle shown in Fig.6a. 


\section{Discussion}

\subsection{Effect of the grain refinement and RMF on the microstructure}

As shown in Fig.3 and Table 2, the GR and RMF have no significant effects on the detected thermal field. According to the simulation results within the CETSOL project [58], when a RMF is applied, a forced melt flow is created during stage II. The maximum value of the flow velocity along the sample axis direction is $0.003 \mathrm{~mm} / \mathrm{s}$ in the center of the sample. The maximum flow velocity is approaching zero at the sample periphery. This forced liquid flow is the main flow during the solidification under the microgravity condition in this experiment. The maximum velocity of liquid flow along the direction along the sample axis is much smaller than the pulling velocity at the level of the solid-liquid interface, which is about $0.20 \mathrm{~mm} / \mathrm{s}$ in stage II. Accordingly, we can expect that the measured thermal field is not affected by the RMF induced forced flow.

The grain refinement of $\mathrm{Al}-7$ wt.\% alloy in B2F1 leads to a CET after the velocity jump, whereas only the development of a finer columnar dendritic microstructure is observed in the non-refined alloy (B2F2) with the same pulling velocity jump and other parameters comparable. As already mentioned above, the higher pulling velocity enhances the constitutional undercooling ahead of the dendrite tips. When the nucleation undercooling of the particles is attained, large amount of equiaxed grains randomly nucleate ahead of the columnar front and start to grow. This definitely blocks the growth of the columnar grains, leading to the inception of the CET, at CET $T_{\min }$. Subsequent grain nucleation efficiently stops the growth of alreadynucleated neighboring equiaxed grains to continue the CET. In B2F1, progressive CET characterized by elongated equiaxed grains is observed. This is mostly attributed to the relatively high temperature gradient in this experiment. Indeed, 
nucleation only takes place in a shorter undercooled region due to the high temperature gradient, preventing the copious and simultaneous nucleation which is necessary to impede the growth of the new nucleated grains. Only a few layers of newly-nucleated grains may form in this case and grains get elongated during the growth.

There is no CET in the non-refined alloy B2F2. Indeed, there are no refining particles in such alloy to achieve the nucleation. Actually, CET in non-refined alloys was reported by many authors and ascribed to the dendrite fragmentation $[17,59,60]$ with the requirement that the dendrite fragments are transported in front of the columnar dendrites $[17,20,61]$. The application of RMF in B2F2 is expected to enhance the dendrite fragmentation and to transport the fragments to the columnar front to trigger CET. A quite large liquid flow velocity along the sample axis, i.e. along the solidification direction, is necessary. However, according to the simulation results, even though the maximum azimuthal flow velocity is about $0.2 \mathrm{~mm} / \mathrm{s}$ in the melt, it is reduced when approaching the solid-liquid interface or mushy zone. Therefore, it might not be sufficient to produce enough fragments. Moreover, the maximum value of the flow velocity induced by the RMF along the sample axis direction is much lower than the growth velocity of the dendrites. Even if the liquid flow velocity would be higher than expected, the maximum flow velocity region would only be confined in the center of the sample, which implies that not enough fragments could be transported to the columnar front. Taking into account these two restrictions, it seems reasonable to assume that CET cannot be triggered by the RMF in stage II for B2F2. 


\subsection{Effect of the surface pore on the microstructure and CET}

As described above, the irregular decrease of $E \%$ and change of decrease slope of DAS are observed in the vicinity of the surface pore regions for both samples (Fig.7). These effects are more apparent in B2F1 sample, concomitantly with the highly elongated grain growth and a sharp increase of EF for B2F1 (Fig.6). These observations suggest that the surface pores affect the solidification process and consequently the microstructure and the CET.

From the post-mortem analysis of the samples, it is difficult to determine the nucleation position. However, if the surface pore forms in or close to the mushy zone $(\mathrm{MZ})$, a deformation of the dendritic network would be expected. As reported by Lesoult et al. [46], the MZ can deform as spongy, with squeezing out of the liquid from the interdendritic region. This $\mathrm{MZ}$ deformation becomes more difficult with the increase of the solid fraction up to the coherency value $[43,44]$. The solid fraction of the dendrite coherency point is very low, about $10 \%$ for large, highly branched dendrite arrays $[45,62]$. For this reason, and considering the large size of the pores and no observation of the dendrite distortion around the pores, the pore most likely forms in the region at temperatures higher than the eutectic isotherm $\left(T_{E}\right)$. In addition, assuming that the porosities form due to the dissolved residual gases, or gases from reactions with the crucible walls, accumulating at the solidification front, it is most likely that the nucleation position of the surface pore is close to the dendrite front, as illustrated in Fig.8, which was also supported by the study of Atwood et al. [63].

During the formation and expansion of the surface pore, the liquid in the vicinity of the pore region can be pushed toward the center of the sample, due to the movement of the pore/liquid interface, as shown in Fig.8a in the 2D longitudinal 
section. Liquid is pushed away from the pore and streamlines radiate from the pore as indicated by the black arrows outside the solid circle line.

At the left side of the pore, the liquid flows toward the eutectic front, oppositely to the solidification direction. At the far side of the pore (bottom of Fig.8a), the flow has the same direction as the solidification direction. In the region close to the pore centerline, the liquid flow is initially perpendicular to the solidification direction, and then gradually turns parallel to the solidification direction (middle of Fig.8a). At the right part of the pore, the liquid flows along the solidification direction.

For $\mathrm{B} 2 \mathrm{~F} 1$, in the region between the eutectic isotherm and the pore center line, $\mathrm{a}$ hotter and Si-poorer liquid is most likely squeezed in, replacing the original liquid and resulting in an increase of the temperature and a decrease of the Si content of the liquid in this region. In this case, the growth of the as-existing dendrites is promoted, yielding the decrease of the $\mathrm{E} \%$ and reducing the DAS decrease rate in this region as shown in Fig.7c. In the region close to the pore center, the squeezed liquid generates a constant but much lower E\% value. In the region at the right of the pore center, the fluid flow coming from the mushy zone can induce a decrease of the temperature and an increase of the Si content of the liquid, leading to the increase of the $E \%$ and rising of the DAS decrease rate in this region, i.e. range of $1 \mathrm{~mm}$ before and after the pore end as shown in Fig.7c.

This liquid flow influences not only the E\% and DAS of the sample, but also the Elongated Factor (EF) of the grain structures. The liquid flow influence on the EF is mainly concentrated in opposite region of the pore in the sample diameter direction (bottom region in Fig.8a). As discussed, the liquid flow in this region is parallel to the growth direction (from left to right in this figure), with the direction close to the sample axis. During the solidification, the solute rejection at the advancing solid-liquid 
interface leads to the build-up of a solute boundary layer [16]. The liquid flow resulting from the pore carries away the Si released by the dendritic network and lowers the Si concentration ahead of the tip. Concomitantly, the new nucleated grains are also carried away from the tip. Therefore, the dendrites grow faster and they do not face competition with new nucleated grains. So, the dendrites are prone to grow along the liquid flow direction and to be more elongated, leading to the grain structures observed at the far side of the pore as indicated by the red circle in Fig.6a. In B2F2 sample, similar liquid flow as shown in Fig.8a is triggered, but with less effect because of the mixing effect of the rotating magnetic field [58] and the lower pore curvature compared with $\mathrm{B} 2 \mathrm{~F} 1$ sample. For the left part of the pore region, the simultaneous increase of the temperature and decrease of solute composition due to the squeeze-in of the liquid lead to the decrease of the E\% and slowdown of the DAS decrease rate similarly to the case of $\mathrm{B} 2 \mathrm{~F} 1$. As concerns the region close to the pore center, the liquid squeeze-out results in the continuous decrease of the E\% and generates the gradually decreasing E\% pattern. However, all these effects are weaker when farther away from the pore.

For the sake of completeness, we have also estimated the strength of the Marangoni flow, which could play a role in this experiment. Indeed, a temperature gradient along the gas/liquid interface may lead to a melt flow from the hot region toward the cold region of the bubble $[39,40,64]$. Although it is difficult to get the exact characteristic of this flow, the maximum value of the Marangoni velocity can be estimated to be much larger than the growth velocity $[40,64,65]$, in a very thin layer clinging close to the pore/liquid interface. However, to obtain quantitative values, some specific simulations should be performed. The Marangoni liquid flow pattern in the region of the surface pore can be speculated as shown in Fig.8b, from the hot to the cold 
liquid region [40,66]. Due to Marangoni effect, hotter and less Si concentration liquid is pushed towards the mushy zone as in the case of flow due to pore expansion, as shown in Fig.8 so that these two kinds of liquid flow in the region around the pore contribute in a same way.

The discussion in section 4.4 indicates that the extra liquid flow, both induced by the pore formation and expansion and also by the Marangoni flow, may change the solidification conditions and consequently affect the microstructure significantly in the pore region. But the dominant factor cannot be determined in this study, based on metallurgical analysis. Some more quantitative analyses, especially for the formation and expansion of the pore, and also simulation about the impact of the pore are needed in the future.

\section{Conclusion}

Two microgravity experiments were carried out in the Material Science Laboratory on board the International Space Station using the Solidification and Quenching Furnace. The influence of the GR, RMF and in particular, of surface pores on the microstructure and CET were studied.

(1) The increase of the furnace pulling velocity from stage I to stage II leads to finer dendrite structure in both refined and non-refined samples. Consequently, a smaller average eutectic percentage and more homogeneous eutectic phase distribution are obtained in stage II. The addition of the GR or RMF show very minor influence on the thermal conditions, and accordingly on the eutectic phase percentage and dendrite arm spacing.

(2) The CET is obtained only for refined alloys but with a progressive mode. Indeed, the rather high temperature gradient decreases the amount of continuous nucleation 
of grains ahead of the solidification front, leading to an elongated equiaxed grain zone and postponing the complete CET. The application of the RMF fails to trigger the CET in B2F2, because the moderate liquid flow velocity resulting from the RMF is not enough to enhance the fragmentation and to take the fragments away from the deep mushy zone to the solidification front.

(3) The formation of the surface pore influences the microstructure by inducing a liquid flow by the pore expansion and Marangoni effect. The E\% decreases and the decrease of DAS induced by the increasing growth velocity in stage II is slowed down at the level of the pore in both samples. Moreover, the extra liquid flow due to the pore strengthens the growth of the dendrite grains along the liquid flow direction, especially on the far side of the defect and, as a result, postpones the CET in B2F1.

\section{Acknowledgement}

This research work is supported by the European Space Agency under the CETSOL (Columnar to Equiaxed SOLidification processes) ESA MAP project, the French National Space Agency (CNES) and the German BMWi/DLR under FKZ 50WM1443. The authors acknowledge Hydro Aluminium Rolled Products $\mathrm{GmbH}$ for providing the alloys used in this paper. We would like to thank F. Băltărețu, O. Budenkova and Y. Fautrelle from SIMAP/EPM Laboratory in Grenoble for numerical modelling of melt flow induced by the rotating magnetic field.

\section{References}

[1] J.A. Dantzig, M. Rappaz, Solidification, EFPL Press, 2009.

[2] H. Jung, N. Mangelinck-Noël, H. Nguyen-Thi, B. Billia, Columnar to equiaxed transition during directional solidification in refined Al-based alloys, J. Alloys Compd., 484 (2009) 739-746. 
[3] J.D. Hunt, Steady state columnar and equiaxed growth of dendrites and eutectic, Mater. Sci. Eng., 65 (1984) 75-83.

[4] H. Jung, N. Mangelinck-Noël, H. Nguyen-Thi, N. Bergeon, B. Billia, A. Buffet, J. Baruchel, CET by fragmentation during the solidification under natural and forced convection of non-refined Al-based alloys, in: Mater. Sci. Forum Trans Tech Publ, 2010, pp. 343-348.

[5] M.A. Martorano, V.B. Biscuola, Predicting the columnar-to-equiaxed transition for a distribution of nucleation undercoolings, Acta Mater., 57 (2009) 607-615.

[6] A.L. Greer, A.M. Bunn, A. Tronche, P.V. Evans, D.J. Bristow, Modelling of inoculation of metallic melts: application to grain refinement of aluminium by $\mathrm{Al}-$ Ti-B, Acta Mater., 48 (2000) 2823-2835.

[7] T.E. Quested, Understanding mechanisms of grain refinement of aluminium alloys by inoculation, Mater. Sci. Technol., 20 (2004) 1357-1369.

[8] S.C. Flood, J.D. Hunt, Columnar and equiaxed growth: II. Equiaxed growth ahead of a columnar front, J. Cryst. Growth, 82 (1987) 552-560.

[9] K.A. Jackson, J.D. Hunt, D.R. Uhlmann, T.P. Seward, On the origin of the equiaxed zone in castings, Transactions of the American Institute of Mining, Metallurgical, and Petroleum Engineers (Incorporated), 236 (1966) 149-158.

[10] D. Ruvalcaba, R.H. Mathiesen, D.G. Eskin, L. Arnberg, L. Katgerman, In situ observations of dendritic fragmentation due to local solute-enrichment during directional solidification of an aluminum alloy, Acta Mater., 55 (2007) 4287-4292.

[11] E. Liotti, A. Lui, R. Vincent, S. Kumar, Z. Guo, T. Connolley, I.P. Dolbnya, M. Hart, L. Arnberg, R.H. Mathiesen, P.S. Grant, A synchrotron X-ray radiography study of dendrite fragmentation induced by a pulsed electromagnetic field in an Al-15Cu alloy, Acta Mater., 70 (2014) 228-239. 
[12] G. Salloum-Abou-Jaoude, H. Nguyen-Thi, G. Reinhart, R.H. Mathiesen, G. Zimmermann, D. Voss, Characterization of Motion of Dendrite Fragment by XRay Radiography on Earth and under Microgravity Environment, Mater. Sci. Forum, 790-791 (2014) 316.

[13] J. Wang, Y. Fautrelle, Z.M. Ren, X. Li, H. Nguyen-Thi, N. Mangelinck-Noel, G.S. Abou Jaoude, Y.B. Zhong, I. Kaldre, A. Bojarevics, L. Buligins, Thermoelectric magnetic force acting on the solid during directional solidification under a static magnetic field, Appl. Phys. Lett., 101 (2012) 251904.

[14] H. Zhong, C. Li, Z. Ren, M. Rettenmayr, Y. Zhong, J. Yu, J. Wang, Effect of interdendritic thermoelectric magnetic convection on evolution of tertiary dendrite during directional solidification, J. Cryst. Growth, 439 (2016) 66-73.

[15] S.N. Tewari, R. Shah, H. Song, Effect of magnetic field on the microstructure and macrosegregation in directionally solidified $\mathrm{Pb}-\mathrm{Sn}$ alloys, Metall. Mater. Trans. A, 25 (1994) 1535-1544.

[16] A. Bogno, H. Nguyen-Thi, A. Buffet, G. Reinhart, B. Billia, N. Mangelinck-Noël, N. Bergeon, J. Baruchel, T. Schenk, Analysis by synchrotron X-ray radiography of convection effects on the dynamic evolution of the solid-liquid interface and on solute distribution during the initial transient of solidification, Acta Mater., 59 (2011) 4356-4365.

[17] L. Abou-Khalil, G. Salloum-Abou-Jaoude, G. Reinhart, C. Pickmann, G. Zimmermann, H. Nguyen-Thi, Influence of gravity level on Columnar-toEquiaxed Transition during directional solidification of Al-20 wt.\% Cu alloys, Acta Mater., 110 (2016) 44-52.

[18] R. Jansen, P.R. Sahm, Solidification under microgravity, Mater. Sci. Eng., 65 (1984) 199-212. 
[19] D.R. Liu, N. Mangelinck-Noël, C.A. Gandin, G. Zimmermann, L. Sturz, H. Nguyen Thi, B. Billia, Structures in directionally solidified Al-7 wt.\% Si alloys: Benchmark experiments under microgravity, Acta Mater., 64 (2014) 253-265.

[20] S. Akamatsu, H. Nguyen-Thi, In situ observation of solidification patterns in diffusive conditions, Acta Mater., 108 (2016) 325-346.

[21] M. Conti, Advection flow effects in the growth of a free dendrite, Phys. Rev. E, 69 (2004) 022601.

[22] A.G. Murphy, R.H. Mathiesen, Y. Houltz, J. Li, C. Lockowandt, K. Henriksson, N. Melville, D.J. Browne, Direct observation of spatially isothermal equiaxed solidification of an Al-Cu alloy in microgravity on board the MASER 13 sounding rocket, J. Cryst. Growth, 454 (2016) 96-104.

[23] D. Langbein, Fluid statics and dynamics in microgravity, J. Phys.: Condens. Matter, 2(1990) SA491-SA498.

[24] N.O. Young, J.S. Goldstein, M.J. Block, The motion of bubbles in a vertical temperature gradient, J. Fluid Mech., 6 (1959) 350-356.

[25] M. Blair, R. Monroe, C. Beckermann, R. Hardin, K. Carlson, C. Monroe, Predicting the occurrence and effects of defects in castings, JOM, 57 (2005) 2934.

[26] J. Campbell, Chapter 9 - Structure, defects and properties of the finished casting, in: Castings (Second Edition), Butterworth-Heinemann, Oxford, 2003, pp. 267-305.

[27] T. Ludwig, M. Di Sabatino, L. Arnberg, D. Dispinar, Influence of Oxide Additions on the Porosity Development and Mechanical Properties of A356 Aluminium Alloy Castings, Int. J. Metalcast., 6 (2012) 41-50. 
[28] C. Pequet, M. Rappaz, M. Gremaud, Modeling of microporosity, macroporosity, and pipe-shrinkage formation during the solidification of alloys using a mushyzone refinement method: Applications to aluminum alloys, Metall. Mater. Trans. A, 33 (2002) 2095-2106.

[29] P.S. Wei, C.C. Huang, K.W. Lee, Nucleation of bubbles on a solidification front—experiment and analysis, Metall. Mater. Trans. B, 34 (2003) 321-332.

[30] M. Ha, W.S. Kim, H.K. Moon, B.J. Lee, S. Lee, Analysis and prevention of dent defects formed during strip casting of twin-induced plasticity steels, Metall. Mater. Trans. A, 39A (2008) 1087-1098.

[31] M.V.A. Bianchi, R. Viskanta, Gas segregation during solidification processes, Int. J. Heat Mass Transfer, 40 (1997) 2035-2043.

[32] J.E. Ramirez, B. Han, S. Liu, Effect of welding variables and solidification substructure on weld metal porosity, Metall. Mater. Trans. A, 25 (1994) 22852294.

[33] Y.F. Wang, X.B. Meng, J.G. Li, X.G. Liu, F. Wang, T. Jin, X.F. Sun, Influence of Directionally Solidified Process on Porosity in the Cross-Section Transitions of Ni-Based Superalloy DZ417G, Rare Metal Materials and Engineering, 45 (2016) 1264-1270.

[34] L. Elmquist, A. Diószegi, Shrinkage porosity and its relation to solidification structure of grey cast iron parts, Int. J. Cast Met. Res., 23 (2010) 44-50.

[35] G.K. Sigworth, C. Wang, Mechanisms of porosity formation during solidification: A theoretical analysis, Metall. Trans. B, 24 (1993) 349-364.

[36] W.R. Wilcox, V.H.S. Kuo, Gas bubble nucleation during crystallization, J. Cryst. Growth, 19 (1973) 221-228. 
[37] H. Meidani, A. Jacot, M. Rappaz, Multiphase-Field Modeling of Micropore Formation in Metallic Alloys, Metall. Mater. Trans. A, 46 (2015) 23-26.

[38] A.G. Murphy, D.J. Browne, Y. Houltz, R.H. Mathiesen, In situ X-ray observations of gas porosity interactions with dendritic microstructures during solidification of Al-based alloys, IOP Conf. Ser.: Mater. Sci. Eng., 117 (2016) 012067.

[39] S.M. O'Shaughnessy, A.J. Robinson, Numerical Investigation of Bubble-induced Marangoni Convection, Ann. N.Y. Acad. Sci., 1161 (2009) 304-320.

[40] P. Arlabosse, N. Lock, M. Medale, M. Jaeger, Numerical investigation of thermocapillary flow around a bubble, Physics of Fluids, 11 (1999) 18-29.

[41] S.M. O'Shaughnessy, A.J. Robinson, Numerical Investigation of Bubble Induced Marangoni Convection: Some Aspects of Bubble Geometry, Microgravity Sci. Technol., 20 (2008) 319-325.

[42] A. Miniewicz, S. Bartkiewicz, H. Orlikowska, K. Dradrach, Marangoni effect visualized in two-dimensions Optical tweezers for gas bubbles, Scientific Reports, 6 (2016) 34787.

[43] B. Meylan, S. Terzi, C.M. Gourlay, A.K. Dahle, Dilatancy and rheology at 0-60\% solid during equiaxed solidification, Acta Mater., 59 (2011) 3091-3101.

[44] C.M. Gourlay, A.K. Dahle, T. Nagira, N. Nakatsuka, K. Nogita, K. Uesugi, H. Yasuda, Granular deformation mechanisms in semi-solid alloys, Acta Mater., 59 (2011) 4933-4943.

[45] N.L.M. Veldman, A.K. Dahle, D.H. StJohn, L. Arnberg, Dendrite coherency of AlSi-Cu alloys, Metall. Mater. Trans. A, 32 (2001) 147-155.

[46] G. Lesoult, C.A. Gandin, N.T. Niane, Segregation during solidification with spongy deformation of the mushy zone, Acta Mater., 51 (2003) 5263-5283. 
[47] T. Sumitomo, D.H. StJohn, T. Steinberg, The shear behaviour of partially solidified Al-Si-Cu alloys, Mater. Sci. Eng., A, 289 (2000) 18-29.

[48] C.M. Gourlay, B. Meylan, A.K. Dahle, Shear mechanisms at 0-50\% solid during equiaxed dendritic solidification of an AZ91 magnesium alloy, Acta Mater., 56 (2008) 3403-3413.

[49] G. Zimmermann, L. Sturz, B. Billia, N. Mangelinck-Noel, H.N. Thi, C.A. Gandin, D.J. Browne, W.U. Mirihanage, Investigation of columnar-to-equiaxed transition in solidification processing of AISi alloys in microgravity - The CETSOL project, in: A. Meyer, I. Egry (Eds.) International Symposium on Physical Sciences in Space, 2011.

[50] C.A. Gandin, B. Billia, G. Zimmermann, D.J. Browne, M.D. Dupouy, G. Guillemot, H. Nguyen-Thi, N. Mangelinck-Noel, G. Reinhart, L. Sturz, S. Mc Fadden, J. Banaszek, Y. Fautrelle, K. Zaidat, A. Ciobanas, Columnar-toEquiaxed Transition in SOLidification Processing (CETSOL): a project of the European Space Agency (ESA) - Microgravity Applications Promotion (MAP) programme, in: R. Roosz, M. Rettenmayr, Z. Gacsi (Eds.) Solidification and Gravity Iv, 2006, pp. 393-404.

[51] B. Billia, C.A. Gandin, G. Zimmermann, D. Browne, M.D. Dupouy, ColumnarEquiaxed Transition in Solidification Processing: The ESA-MAP CETSOL Project, Microgravity Sci. Technol., 16 (2005) 20-25.

[52] Q. Han, S. Viswanathan, Microstructure Prediction in A356 Alloy Castings, In: Peterson RD, editor. Light metals. Warrendale, PA: TMS; (2008) 609-615.

[53] M. Hainke, J. Friedrich, G. Müller, Numerical study on directional solidification of AISi alloys with rotating magnetic fields under microgravity conditions, J. Mater. Sci., 39 (2004) 2011-2015. 
[54] C.A. Gandin, Experimental Study of the Transition from Constrained to Unconstrained Growth during Directional Solidification, ISIJ Int., 40 (2000) 971 979.

[55] C.A. Gandin, From constrained to unconstrained growth during directional solidification, Acta Mater., 48 (2000) 2483-2501.

[56] V.B. Biscuola, M.A. Martorano, Mechanical Blocking Mechanism for the Columnar to Equiaxed Transition, Metall. Mater. Trans. A, 39 (2008) 2885-2895.

[57] I. Steinbach, R. Prieler, Deterministic nucleation model for equiaxed solidification, ASME Heat Transfer Div Publ HTD, 284 (1994) 69-74.

[58] G. Zimmermann, Estimation of the influence of RMF on the melt flow and segregation in CETSOL2\#2 Flight experiment, CETSOL project internal report, (2012).

[59] L. Sturz, G. Zimmermann, Investigations on columnar-to-equiaxed transition in binary al alloys with and without grain refiners, in: R. Roosz, M. Rettenmayr, Z. Gacsi (Eds.) Solidification and Gravity Iv, Trans Tech Publications Ltd, StafaZurich, 2006, pp. 419-424.

[60] H. Jung, N. Mangelinck-Noël, H.N. Thi, B. Billia, L. Sturz, G. Zimmerman, Columnar to equiaxed transition in nonrefined Al-based alloys during directional solidification in microgravity and on earth, in: SP07, 5th Decennial International Conference on Solidification Processing, Sheffield, UK, 2007.

[61] A. Hellawell, S. Liu, S.Z. Lu, Dendrite fragmentation and the effects of fluid flow in castings, JOM, 49 (1997) 18-20.

[62] L. Arnberg, G. Chai, L. Backerud, Determination of dendritic coherency in solidifying melts by rheological measurements, Mater. Sci. Eng., A, 173 (1993) 101-103. 
[63] R.C. Atwood, P.D. Lee, A three-phase model of hydrogen pore formation during the equiaxed dendritic solidification of aluminum-silicon alloys, Metall. Mater. Trans. B, 33 (2002) 209-221.

[64] L.G. Napolitano, R. Monti, G. Russo, Marangoni convection in one-liquid and 2liquid floating zones, Naturwissenschaften, 73 (1986) 352-355.

[65] V.S. Avduyevsky, S.D. Grishin, L.V. Lescov, Some physical aspects of unidirectional crystallization in microgravity, Acta Astronaut., 9 (1982) 583-588.

[66] S. Barsi, M. Kassemi, J.I.D. Alexander, Effects of void-induced convection on interface morphology and segregation during low-g solidification, Int. J. Heat Mass Transfer, 47 (2004) 5129-5137. 
surface pore

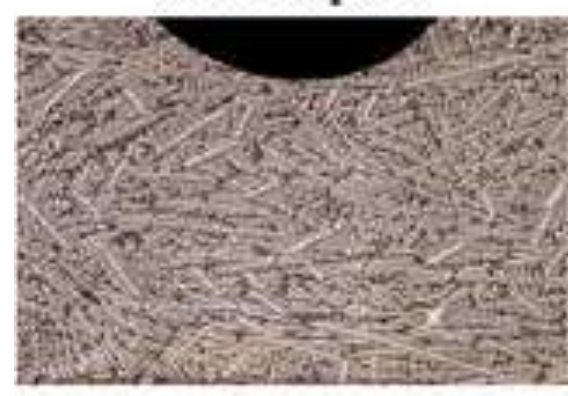

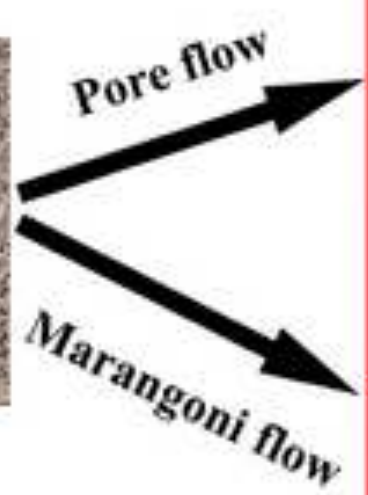

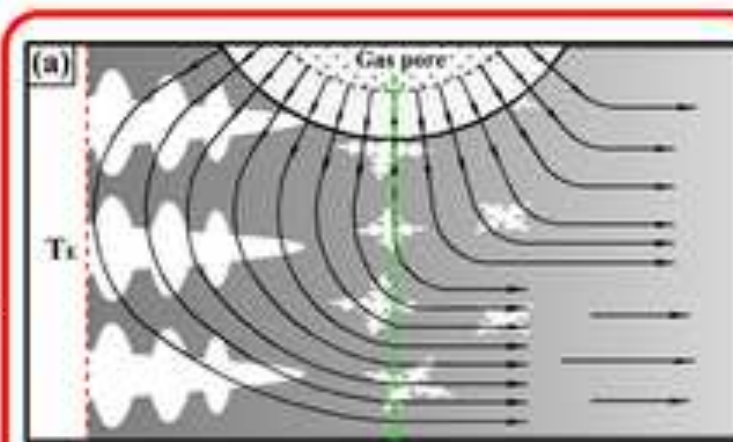

(b)

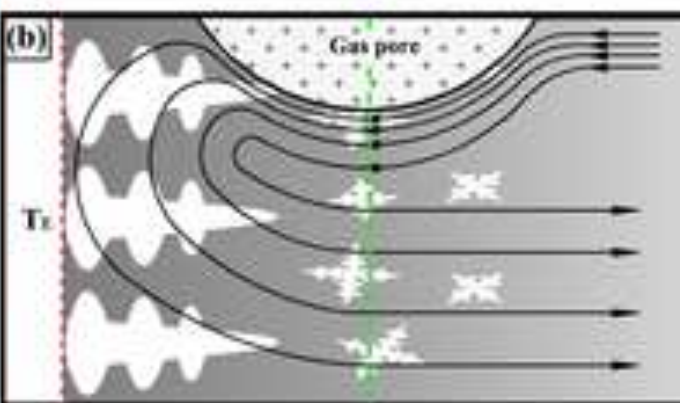

Solidification direction

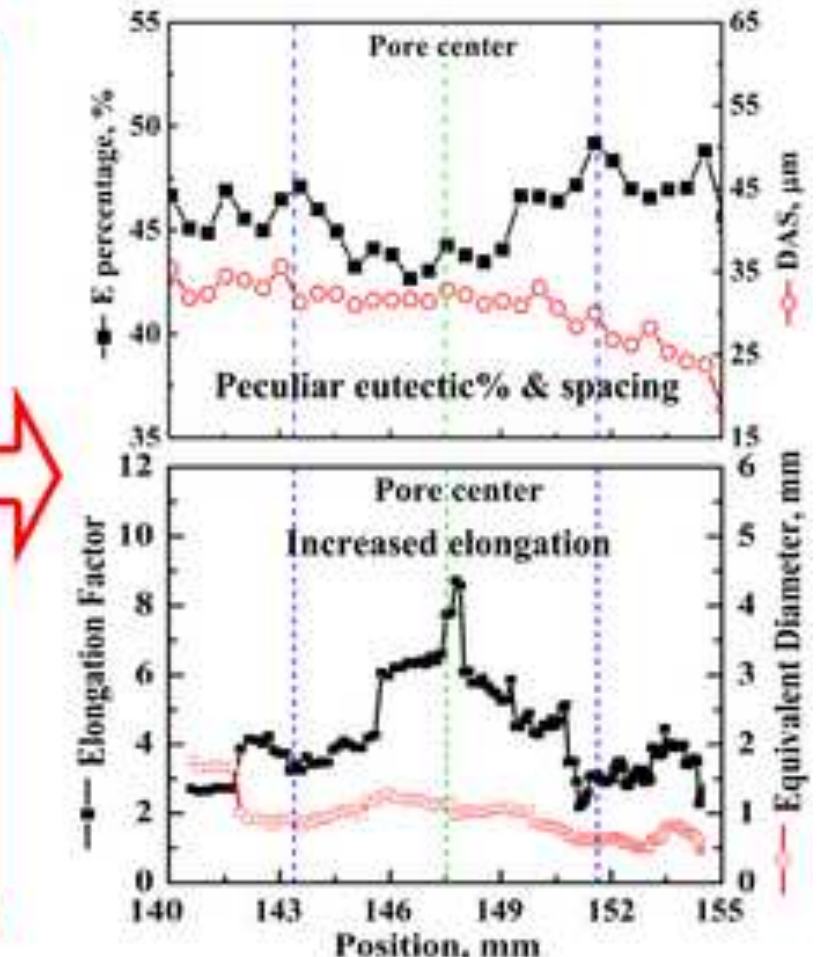


1. Solidification experiments were carried out in the International Space Station.

2. The columnar to equiaxed transition (CET) is obtained only for refined alloys.

3. A moderate rotating magnetic field fails to trigger CET in non-refined alloy.

4. The surface pore influences the microstructure, decreasing eutectic percentage.

5. The extra liquid flow due to the pore can postpone CET. 


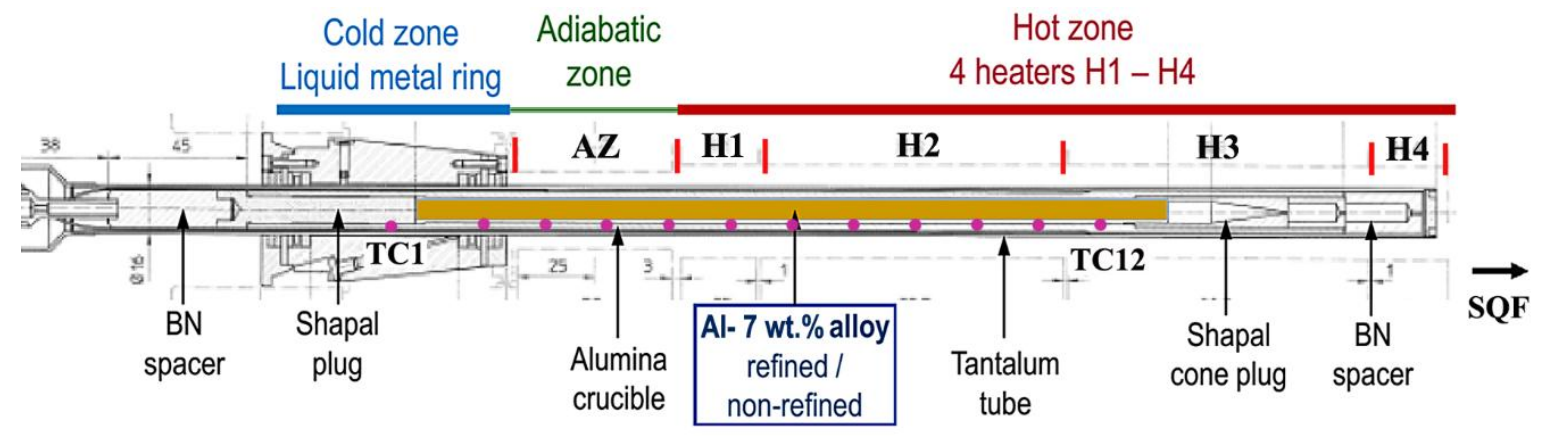

Fig. 1. Sketch of a CETSOL Batch 2a cartridge MSL-SCA integrated in the MSL-SQF furnace showing the situation before solidification with the integrated Al - 7 wt.\% alloy sample. 


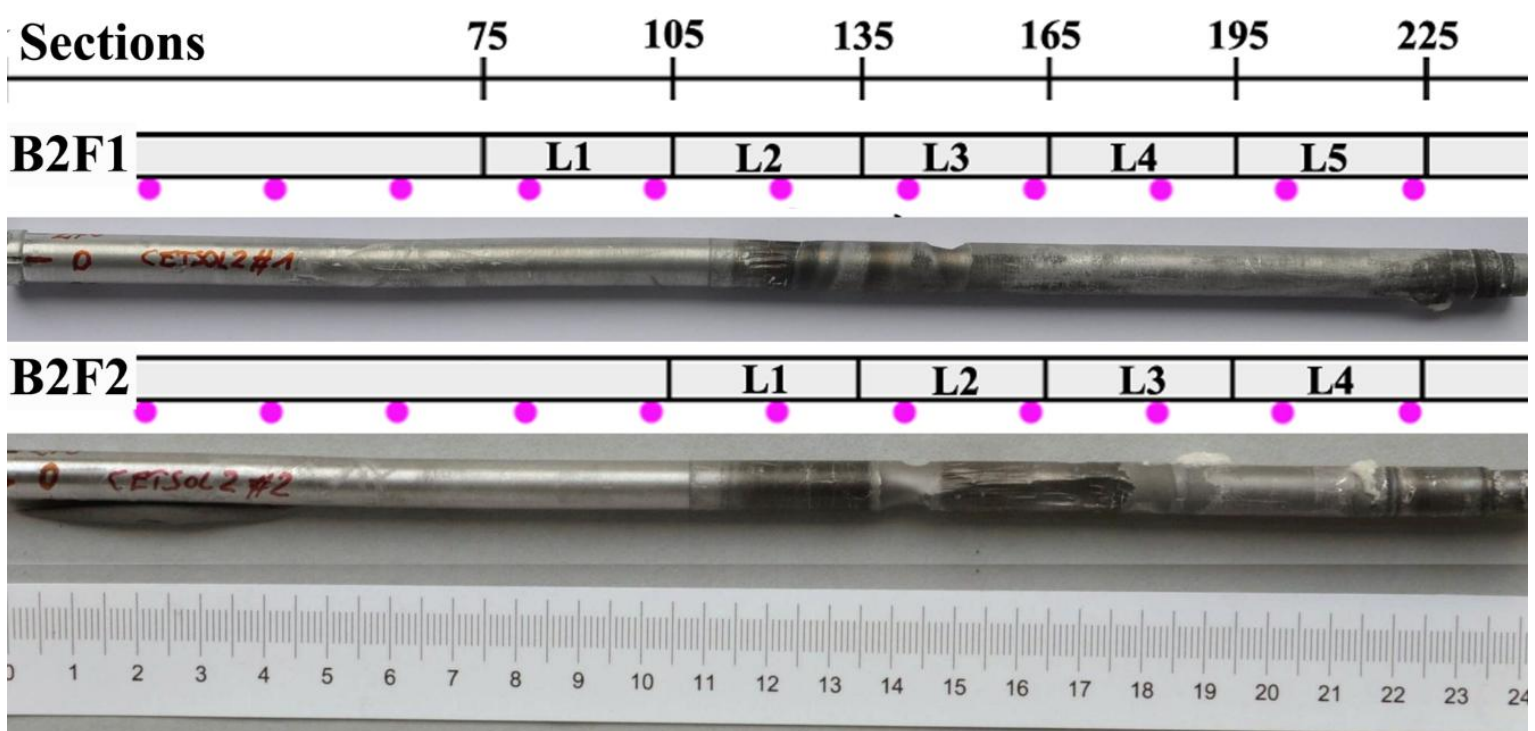

Fig.2. Optical images of the processed samples B2F1 and B2F2 and schematics of the cutting positions of the two samples. The purple dots indicate the locations of the thermocouples TC2-TC12. Numbers on the top indicate the distance from the sample bottom in $\mathrm{mm}$. 

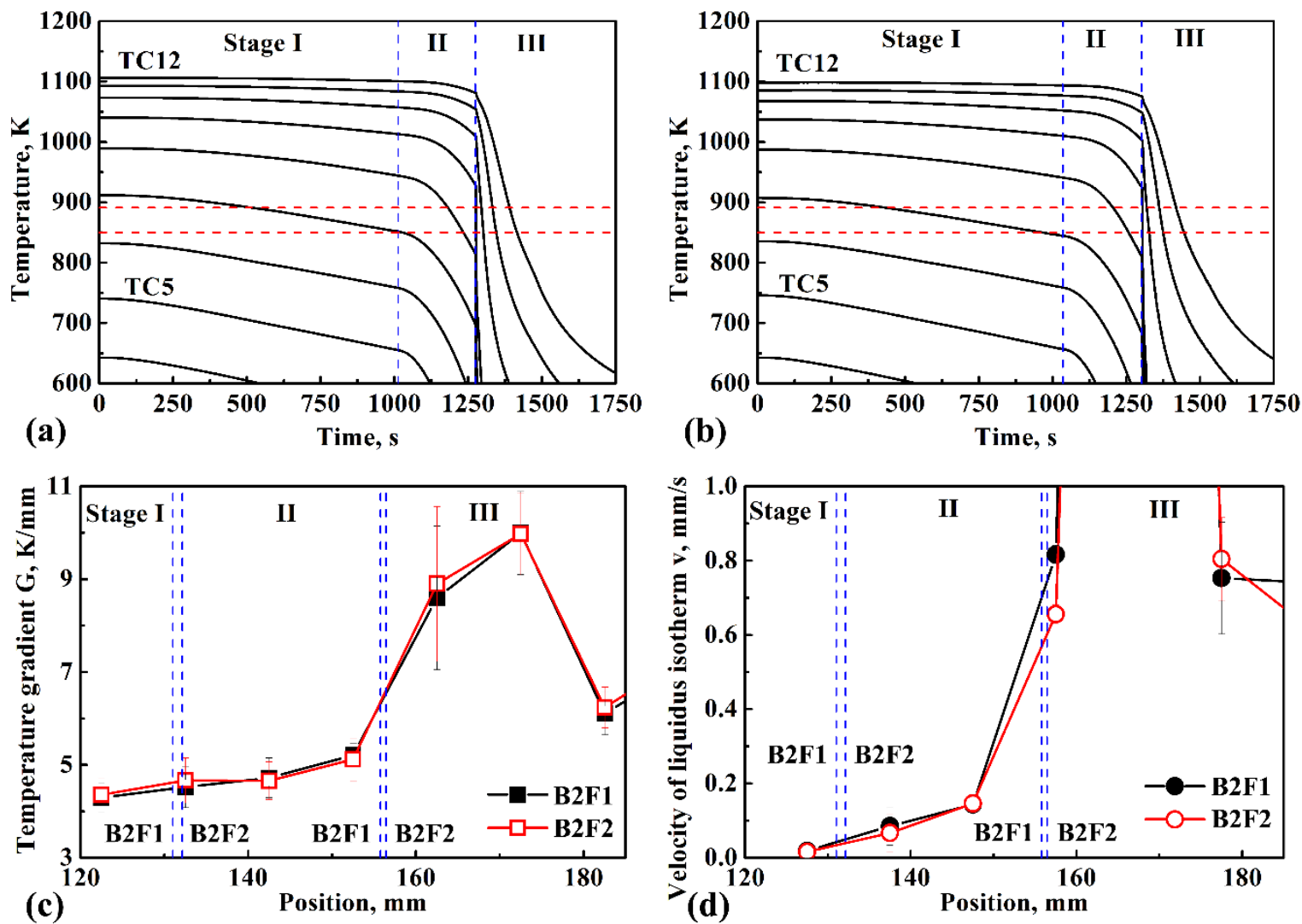

Fig.3. Recorded temperature curves at thermocouple positions TC5 to TC12 (Fig.1) for (a) B2F1 and (b) B2F2. Liquidus and eutectic isotherms $\left(T_{L}=891 \mathrm{~K}\right.$ and $\left.T_{E}=850 \mathrm{~K}\right)$ are indicated with red horizontal dashed lines. (c) Temperature gradient ahead of the liquidus isotherm and (d) average velocity of the liquidus isotherm during the solidification. The boundaries between the different solidification stages are indicated with blue vertical dashed lines. 


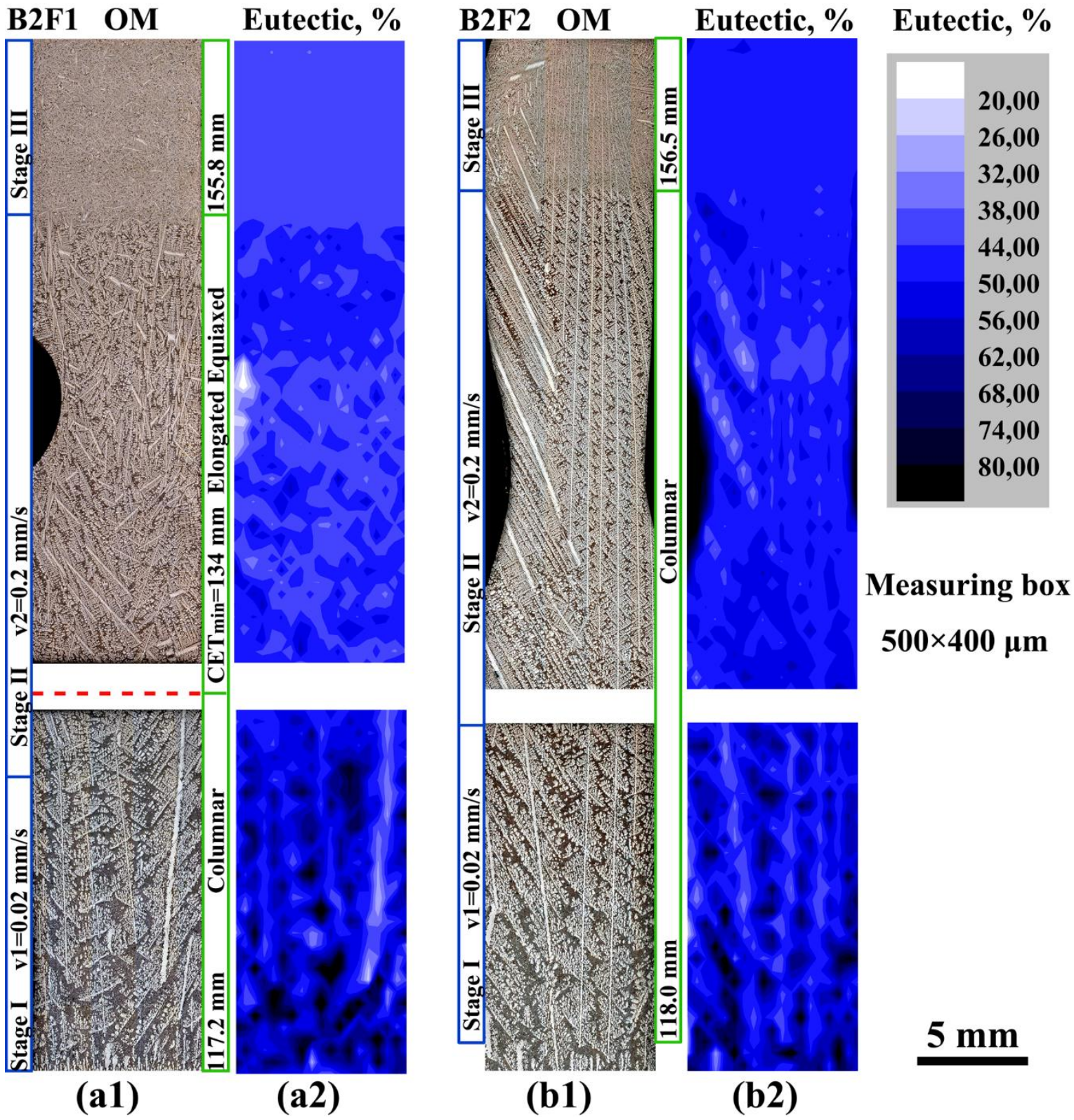

Fig.4. Microstructure obtained with optical microscope (OM) along longitudinal sections (a1 and b1) and eutectic phase percentage distribution map (a2 and b2) of B2F1 and B2F2 in the region of the transition from stage I to stage II. 

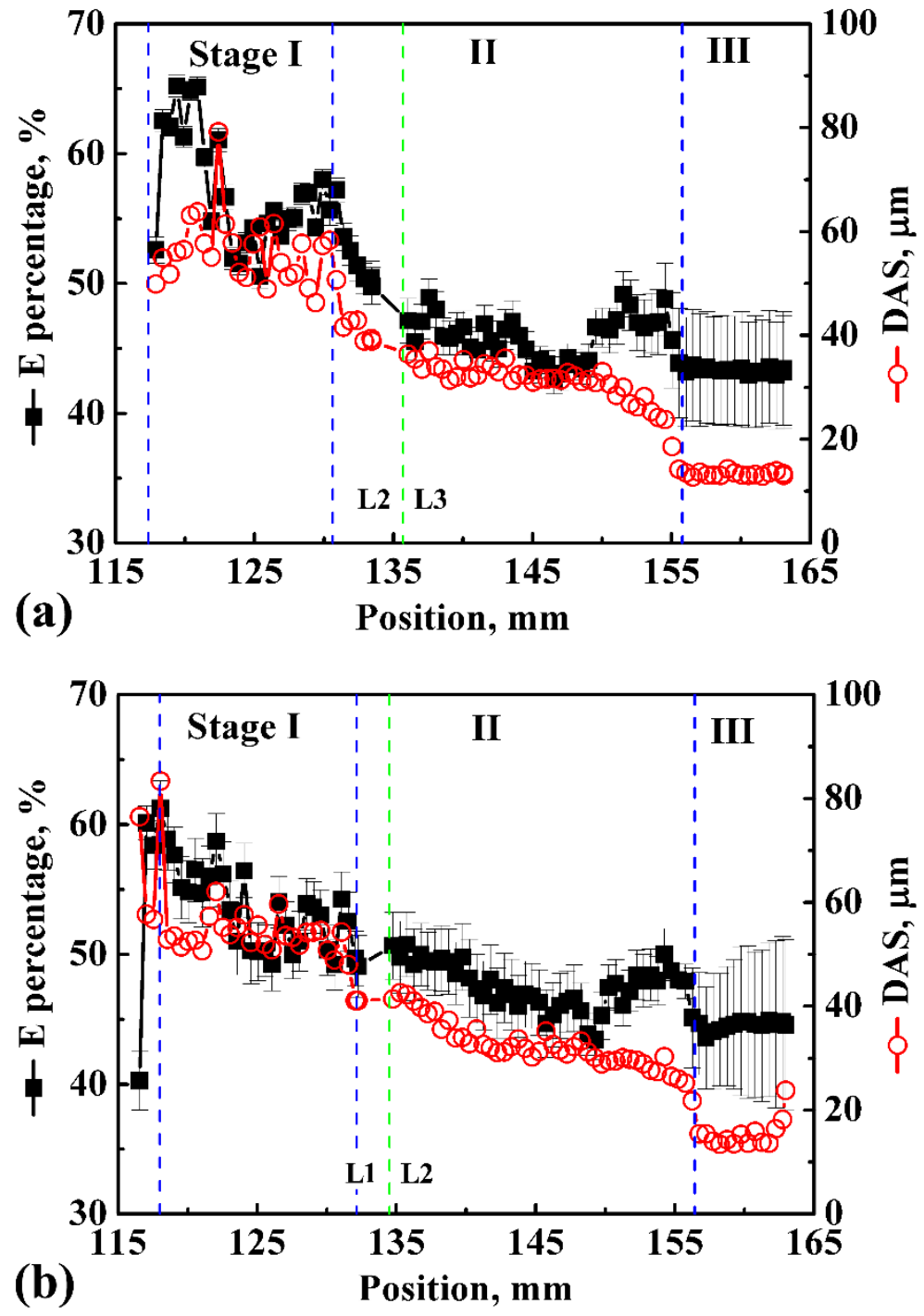

Fig.5. Mean eutectic percentage and DAS vs. position along the longitudinal direction of the sample for (a) B2F1 and (b) B2F2 for stage I to stage III. The blue dash lines show the stages transition positions and the green dash lines show the sections cutting position. 


\section{Solidification direction}

(a)

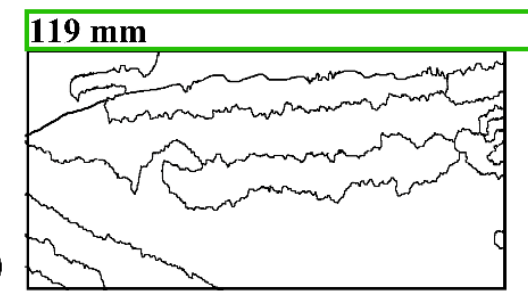

$135 \mathrm{~mm}$
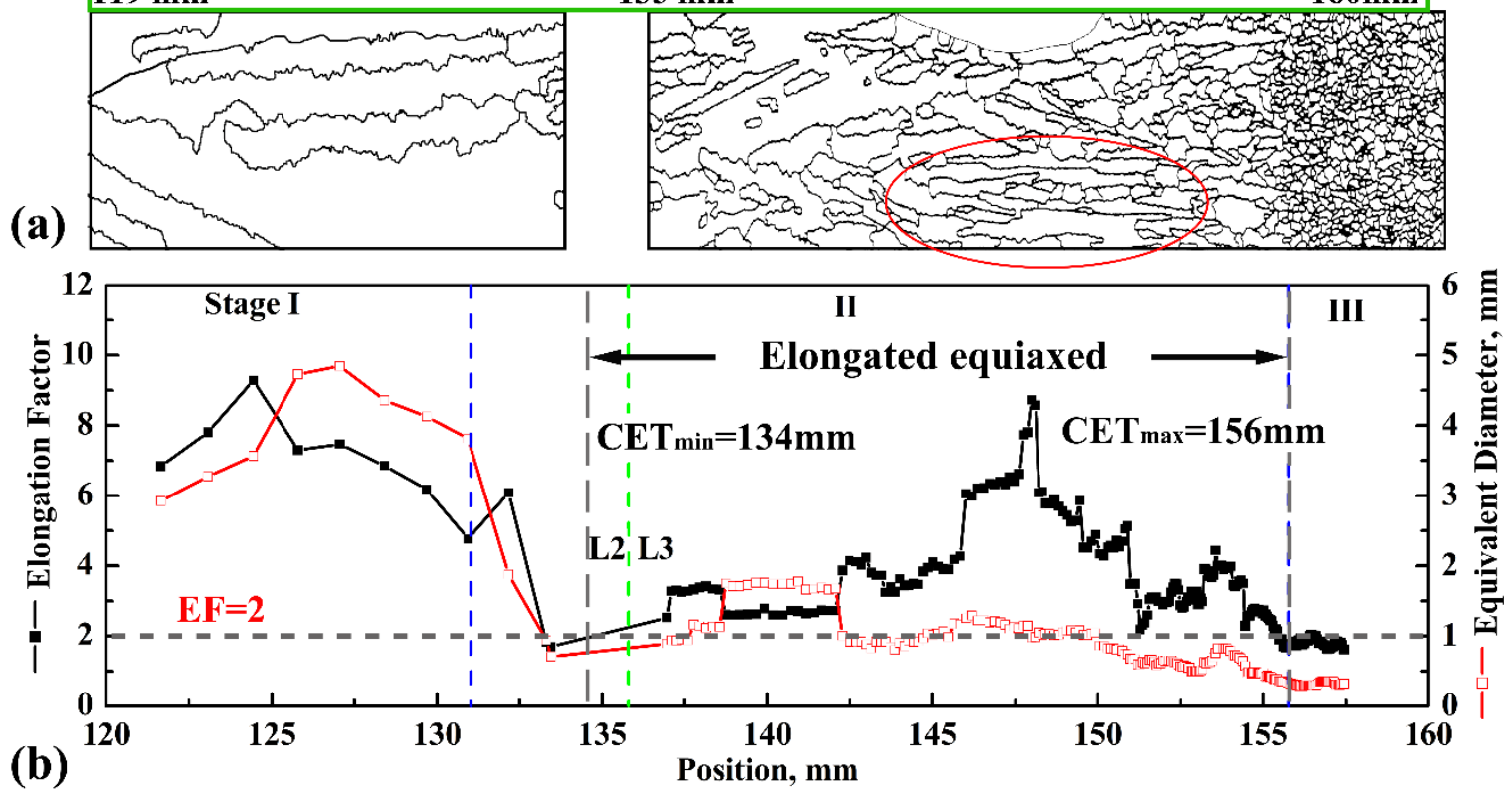

Fig.6. (a) Experimental grain contours revealed by the EBSD maps and (b) Longitudinal profiles of averaged elongation factor and equivalent diameter for longitudinal crosssections L2 to L3 of B2F1 sample. The blue dash lines in (b) show the stages transition positions and the green dash line shows the sections cutting position. 

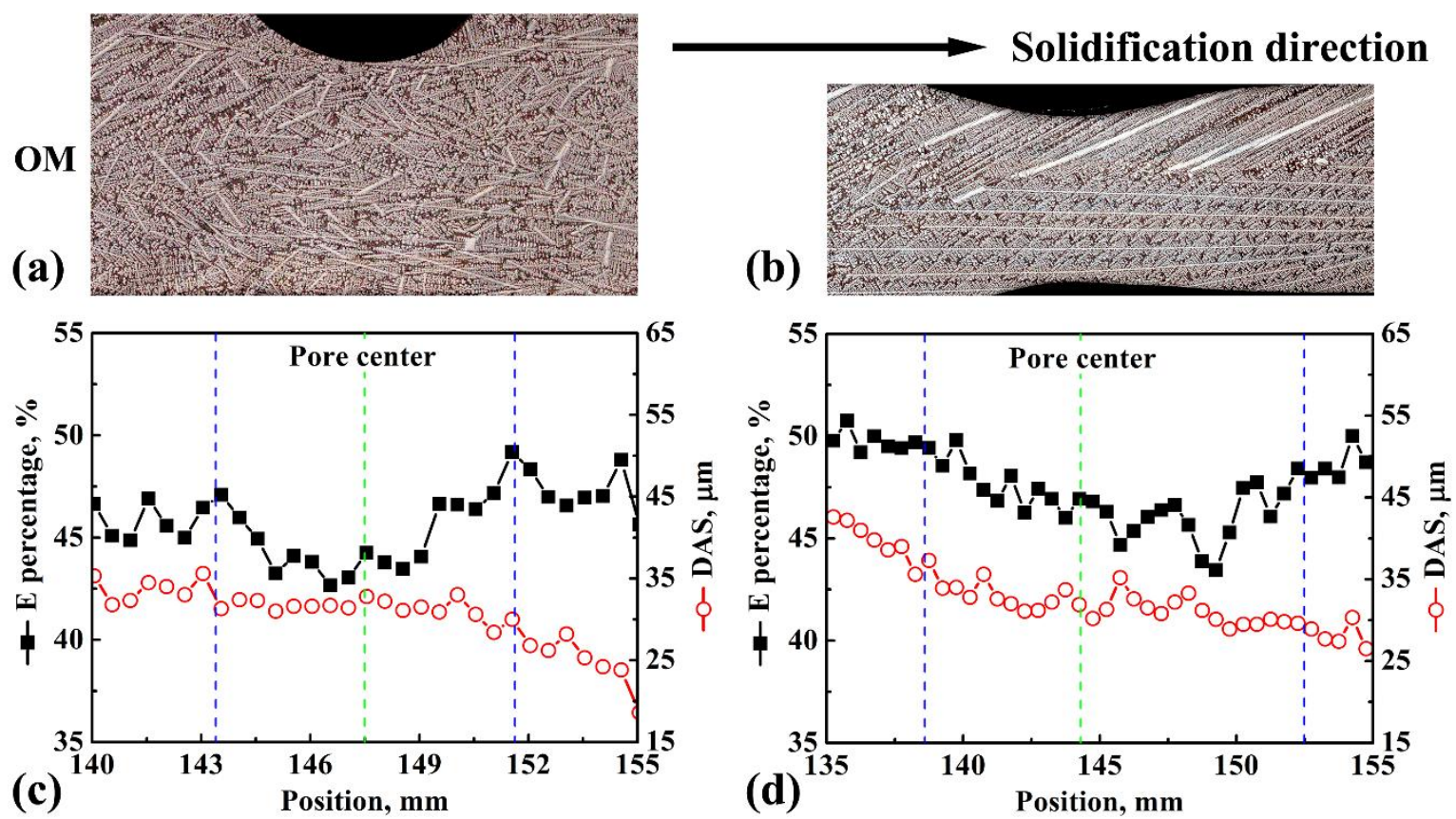

Fig. 7. Microstructure (a, b) and corresponding longitudinal E\% (black cubes) and DAS (red circle) profiles (c, d) with the same length range around the surface pore regions for $\mathrm{B} 2 \mathrm{~F} 1(\mathrm{a}, \mathrm{c})$ and B2F2 $(b, d)$. The solidification direction is from the left to the right for both samples as shown by the black arrow. The green dash lines in (c, d) show the centerline position of the pores, and the blue dash lines show the range impacted by the pore. 

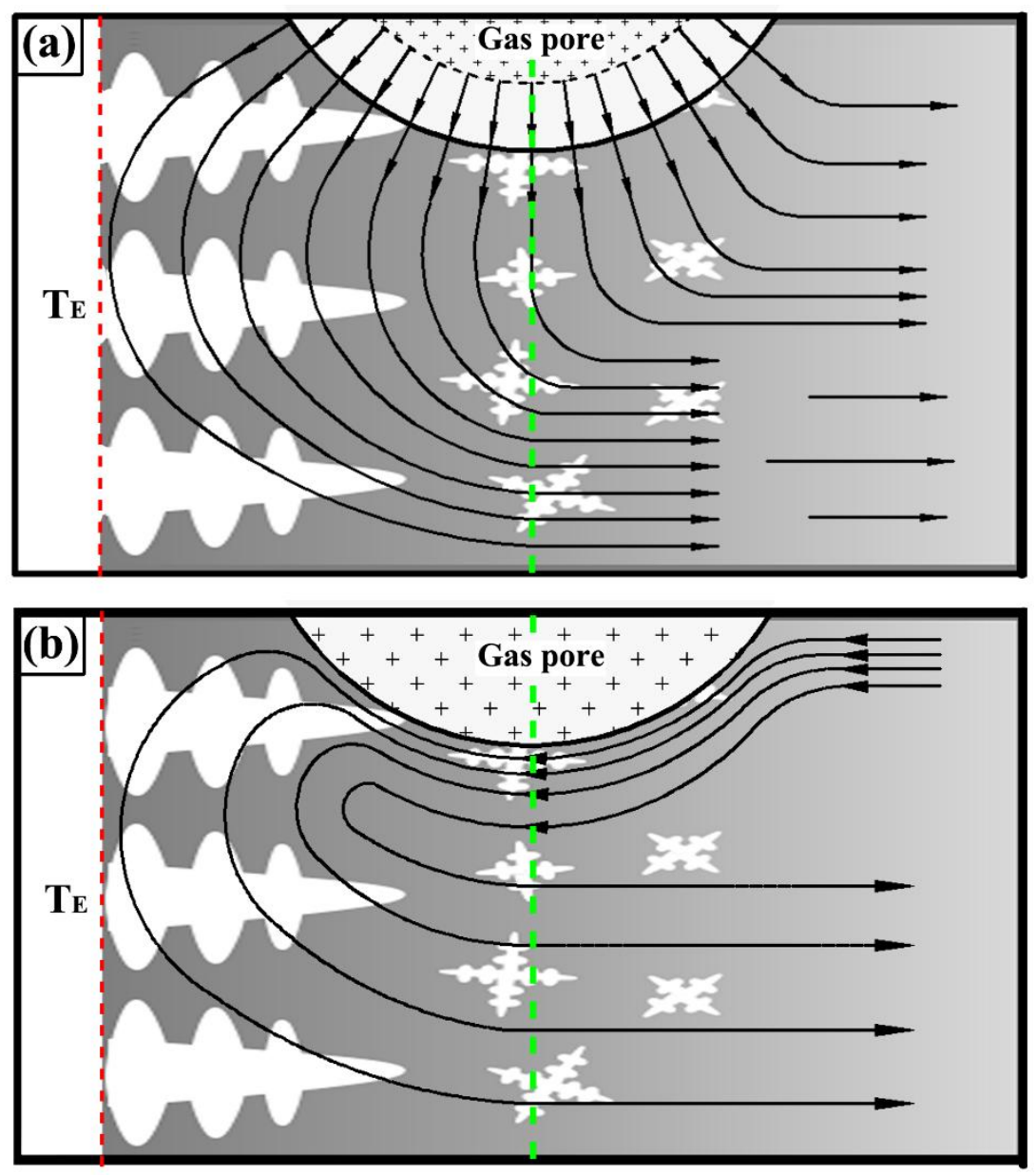

Solidification direction

Fig.8. Schematic pattern of the position of the pore formation and the liquid flow resulting from (a) the formation and expansion (from the black dash line downward to the solid line) of the surface pore, and (b) the Marangoni flow. $T_{E}$ and the red dash lines represent the eutectic isotherm. The green dash lines represents the centerline of the pore. 